\title{
Didáctica y lengua en el chileno Nuevo Método de Educación para el uso de las Escuelas del Campo (1832)
}

\author{
Sonia Almau Almau* \\ Universidad de Zaragoza, España
}

\begin{abstract}
Resumen
El Nuevo Método de Educación para el uso de las Escuelas del Campo es un documento impreso de 1832 redactado por el Padre Mújica, del Colejio y Chacra de Apoquindo de la Recoleta Dominica, que encontramos en el Archivo General Andrés Bello. Se trata de un valioso documento en materia educativa puesto que en él se recoge de forma práctica un método de enseñanza dialógico en el que, a través de preguntas y respuestas, se exponen los conocimientos que los alumnos debían adquirir sobre diversas materias escolares. Pero no solo interesante resulta este impreso para conocer los métodos didácticos de la época, sino que además nos ofrece una gran muestra lingüística para analizar algunos aspectos gramaticales y léxicos, y, especialmente, lo relativo a las formas de tratamiento, de las que presenta una amplia casuística.
\end{abstract}

Palabras clave: español de Chile, aspectos gramaticales y léxicos, formas de tratamiento, método de enseñanza.

Para correspondencia, dirigirse a: Sonia Almau Almau (sonialmau@gmail.com), Departamento de Lingüística General e Hispánica, Facultad de Filosofía y Letras, Universidad de Zaragoza, Pedro Cerbuna 12, 50009 Zaragoza, España. 
Didactics and language in the Chilean document Nuevo

MÉTODO DE EDUCACIÓN PARA EL USO DE LAS ESCUELAS DE CAMPO

Abstract

The Nuevo Método de Educación para el uso de las Escuelas del Campo is an 1832 printed document, found in the Archivo General Andrés Bello and written by Padre Mujica, who belonged to the Colejio y Chacra de Apoquindo de la Recoleta Dominica. It is a valuable document on education, as it contains a practical dialoguebased teaching method which reveals, by means of a question-andanswer logic, the knowledge that pupils should acquire on various school subjects. Not only is this printed document useful to get a glimpse of how the teaching methods were at that time, but it also provides us with a rich linguistic sample that serves us to analyze some grammatical and lexical aspects, especially the forms of treatment, of which it presents abundant instances.

Keywords: Chilean Spanish, grammatical and lexical aspects, forms of treatment, teaching method.

Recibido: 07/04/14 Aceptado: $12 / 03 / 15$

\section{LA IMPORTANCIA DE LA EDUCACIÓN A PRINCIPIOS DEL XIX. CONTEXTUALIZACIÓN DEL DOCUMENTO}

$\mathrm{Al}$ estudiar los documentos de principios del XIX relativos a la enseñanza, se observa, entre otras, la preocupación de tratadistas, eruditos y profesores por dos aspectos: el método didáctico utilizado y la necesidad de extender la educación al pueblo llano. Uno de los documentos impresos más significativos en materia de educación que recoge ambos temas es el Nuevo Método de Educación para el uso de las Escuelas del Campo, redactado por el Padre Mújica, del Colejio y Chacra de Apoquindo de la Recoleta Dominica, que encontramos en el Archivo General Andrés Bello ${ }^{1}$.

\footnotetext{
1 Impreso 1097, 969. A partir de aquí mencionaremos el documento por medio de la abreviatura Campo.
} 
Es preciso tener en cuenta que la educación en Chile hasta principios del ochocientos se había desarrollado únicamente a través del método escolástico ${ }^{2}$ y carecía de un programa bien estructurado, lo que perjudicaba el avance educativo. La prescripción de un método será la inquietud capital de las grandes mentes intelectuales, entre ellos los liberales ${ }^{3}$. En Campo, el método de enseñanza que utiliza el Padre Mújica es de carácter dialógico; se trata de una representación teatral que los niños de este colegio rural hicieron "a presencia de un pueblo como de novecientas personas de ambos sexos" (1), en la que, a través de preguntas y respuestas que hacen diversos personajes, se van exponiendo conocimientos sobre el catecismo y la Historia Sagrada, Geografía, Historia y Aritmética.

Las respuestas no dejan de ser informativas en cuanto que nos muestran en qué grado estaban desarrolladas las ciencias y las creencias que sobre muchos temas diversos tenían los hombres del momento. Así, por ejemplo, sobre geografía se dice:

P. ¿Y cuáles fueron los primeros hombres pobladores de la América?

R. Se dice que los tártaros fueron probablemente sus primeros pobladores.

P. ¿Y también fueron los Tártaros los primeros pobladores de este suelo chileno?

R. Los mejores autores afirman hoi que no, sino con mucha probabilidad los Hebreos.

Por otra parte, la preocupación por hacer llegar la educación a las clases más populares es patente en los escritos de la época. De este modo, en el periódico independentista la Aurora de Chile son numerosas las noticias que aluden a la necesidad de extender la educación a todos los niveles sociales ${ }^{4}$,

2 Decía Camilo Henríquez en la Aurora de Chile: "el método escolástico, los planes de estudio de las escuelas, los óbices que ha encontrado la vulgarización de los libros útiles, han influido poderosamente en el atraso de las letras" $\left(\mathrm{n}^{\circ} 13,7\right.$ de mayo de 1812).

Así, por ejemplo, en 1825 el señor Lozier, ingeniero geógrafo en jefe, impulsa la creación de una sociedad de estudios destinada a "estudiar y propagar los nuevos métodos elementales de instrucción y educación" (Feliú Cruz 1966 / 1825: 439). Esta sección, formada por miembros reputados de la sociedad santiaguina, entre ellos, por ejemplo, el director de la República, se dividía en cuatro secciones: Letras, Ciencias, Artes e Industria. Una de las labores de esta sociedad es la redacción de un periódico llamado El Redactor de la Educación en el que se publican las sesiones de la sociedad y los nuevos métodos de enseñanza, adoptados principalmente del extranjero.

4 En muchos artículos de este periódico se hace alusión a la construcción de espacios públicos de enseñanza para los pobres, como por ejemplo la "escuela pública de primeras letras y principios de latinidad" que es levantada por iniciativa de Fr. Domingo de Velasco (Aurora 
o, dicho de otro modo, a la idea de que "la ilustración debe hacerse popular" (Aurora $\mathrm{n}^{\mathrm{o}}$ 13, 7 de mayo de 1812)

No solamente los nobles y los ricos deberían ser doctrinados en estos principios, sino los plebeyos, los artesanos, los labradores, y mucha parte de las mugeres. Si estas artes se difundieran de las capitales a las villas, y de estas a las aldeas, producirían los admirables efectos de dar a toda la nación un cierto ayre de civilidad, y unas modales cultas; de introducir en las familias el buen orden y la economía; de corregir la educación, que por lo común se entiende mal; de modificar los ingenios de muchos, enseñándoles a hacer el uso que deben de los talentos que Dios les ha dado; y finalmente de perfeccionar las artes, haciéndolas más expeditas, más comunes, y más útiles (Aurora $\mathrm{n}^{\circ} 9,9$ de abril de 1812).

Décadas más tarde, en su "Discurso pronunciado en la Instalación de la Universidad de Chile el 17 de septiembre de 1843", Andrés Bello insistirá también en la necesidad de extender la educación básica:

$[O]$ tros pretenden que el fomento dado a la instrucción científica se debe de preferencia a la enseñanza primaria. Yo ciertamente soy de los que miran la instrucción general, la educación del pueblo, como uno de los objetos más importantes y privilegiados a que pueda dirigir su atención el gobierno; como una necesidad primera y urgente; como la base de todo sólido progreso; como el cimiento indispensable de las instituciones republicanas (1458).

En Campo, el Padre Mújica, además de presentar un método claro y didáctico de aprendizaje, insiste en la bondad de acercar la educación al medio rural:

$\mathrm{n}^{\circ}$ 2, 14 de enero de 1813). En otra noticia de ese mismo número de la Aurora chilena se habla de la reedificación del antiguo colegio de San Carlos, al que se le ha unido la Academia de Matemáticas, el Seminario de Indios y las aulas de primeras letras y latinidad, "para que todos los jóvenes de la capital y de las provincias que quieran recibir enseñanza, o en calidad de alumnos, o de solo concurrentes, oygan lecciones desde los rudimentos de la religión, y el alfabeto, hasta la conclusión de las ciencias abstractas, y las de demostración".

5 Para llevar a cabo este proyecto, una de las medidas propuestas por fray Camilo Henríquez en el número 41 de la Aurora de Chile, con fecha de 19 de noviembre de 1812, es la elaboración de un catecismo patriótico claro y sencillo, que se repartiese por todas las escuelas para que fuera aprendido de memoria por los niños y se recitase en las plazas con el objetivo de extender así ciertos valores cívicos entre todas las clases sociales, en ciudades y pueblos. 
Como parece que en estos tiempos no se pensase por dicha en otra cosa que en la educación y en la enseñanza de nuestra juventud, y no solo en la juventud de esta capital de Chile, sino también en todos los puntos de la República y aún en los más pequeños pueblecitos, en las haciendas y en los campos se hayan abierto escuelas o a espensas del gobierno o a costa de los mismos que las han abierto en sus lugares... $(1)^{6}$.

Al finalizar la exposición de la representación teatral, su autor insiste en la emoción que causó el acto en los presentes, sobre todo al ver a los niños más pobres aplicados en el estudio:

y porque se forme (si es posible) un cabal o justo concepto de lo dicho... han asistido varias personas respetables, a quien se les ha visto verter no pocas lágrimas de gozo, o de ternura, y a otras prorrumpir en expresiones fuertes y significativas de sorpresa, al ver en medio del campo y de la miseria y desnudez de pobres criaturas como arraigados ya conocimientos que hasta aquí habían sido esclusivos de la juventud de rango y distinción. "Mejor es ver esto que estar en la plaza de Roma", dijo de estos actos un gran talento, que por no sonrojarlo no se nombra... una señora de mui buenos principios y todas circunstancias dijo con gracia no común por uno de estos actos, que a ella le habían dado como escalofríos de ver tanto rotito saber tanto y un patriota demaciado encendido, pero que suele electrizarse en estos casos (en un examen privado que les hizo a los niños) estendiendo los brazos y mostrando las palmas de las manos, dijo con espresión: aquí trajera yo a don Manuel Salas para que presenciara y oyera esto... Últimamente, a la circunspección de S.E. el Presidente del Estado, que quiso se ejecutase este acto en su presencia, tal vez en un transporte o de admiración o de contento, se le escapó y se le oyó decir: "no es posible, sin verlo, formar concepto de esto, esto es mui lindo" (49-50).

6 En otro pasaje se dice: “y si fuese posible, debería publicarse en él un edicto más jeneral que aquél de Augusto César, en que se mandase que todo joven de toda clase y condición que fuese, se había de educar precisamente desde los siete u ocho años de su edad, hasta quedar perfectamente instruido en la moralidad de sus acciones, en la lectura y escritura, en los principios de aritmética y aún en la madre y reina de muchas lenguas, la latina, por ser estas las llaves con que se abren con gran facilidad todas las puertas de las ciencias" (5). 


\section{ASPECTOS GRAMATICALES DE CAMPO}

Este documento, además de ser un testimonio valioso de los métodos didácticos que se utilizaban en la época, presenta rasgos gramaticales dignos de ser destacados. Así, por ejemplo, encontramos el uso del artículo femenino delante del nombre en "los conocí a todos, y también a la reina Vasthi y a la Ester" (38). El uso del artículo determinado delante de nombres propios es hoy en España un signo de incultura y suele estar relegado a contextos rurales y populares. No obstante, no ocurre lo mismo en Chile, donde el uso del artículo -sobre todo con nombres propios de mujer- puede escucharse incluso en informativos y entre gente culta. Oroz (1966: 371) ya señaló esto: "el empleo del artículo con nombres propios no se limita en Chile al habla rústica y vulgar, sino que se puede considerar casi como norma general. Su omisión suena a cursilería, tratándose de nombres femeninos... los nombres propios masculinos se usan luego con artículo, luego sin él".

Así mismo, encontramos ejemplos del uso antiguo del demostrativo antepuesto al posesivo que acompaña al sustantivo, un uso muy habitual en la documentación de esta época, tanto impresa como escrita. Aquí aparecen los siguientes casos:"y ese tu libro, ¿qué contiene, Astaroth?" (9), "este nuestro enemigo contumaz ha hecho correr en el abismo..." (29). En este sentido, es importante indicar que en el español americano pervive aún este uso, un rasgo que en el español peninsular ha quedado relegado a la lengua culta y a un registro formal.

La tendencia a colocar artículo con el relativo ha progresado más en España que en América, quizás por su mayor apego a la tradición, de ahí que sean innumerables los casos en los que el relativo aparece sin el correspondiente artículo antepuesto en todo tipo de documentos. En este texto encontramos, por ejemplo, los siguientes casos: “¿qué entendéis por el infierno a que bajó Cristo Nuestro Señor después de muerto?” (13), “quién fue el rey Asuero de que habla la Escritura" (35), "ojalá... nos enseñaras esta historia sagrada a que estamos tan aplicados" (39).

Significativo es el uso de cualesquiera con valor de singular en el siguiente ejemplo de Campo:"así será honrado cualesquiera a quien el Rei quisiese honrar" (38). Oroz explica la tendencia a utilizar el plural con valor de singular "no sólo en la lengua vulgar, sino también en niveles sociales 
superiores", un uso que fue muy común en la lengua antigua (1966: 381) y, en general, en toda Hispanoamérica, como también explicó Kany ${ }^{7}$.

Además de la importancia de las formas de tratamiento personal a las que dedicaremos un epígrafe aparte, hay que destacar la aparición de un caso con proclisis del pronombre átono, un uso ya casi inusual en la época ${ }^{8}$ : "es el Hijo de Dios vivo que se hizo hombre por nos redimir y dar ejemplo de vida" (13).

En cuanto al verbo, cabe indicar el uso del pretérito perfecto compuesto. A pesar de que en la actualidad este tiempo tiene un uso muy restringido en el español de América, en este documento se observa una abundante utilización. Por poner solo algún ejemplo: "¿y es cierto, como te acusa Leviathan, lo que has informado en esta escuela al Infierno?... es cierto que todo lo he dicho y lo he informado a mis cabernas y mucho más, y no he dicho una palabra de mentira" (10), "y así todo es mentira cuando has dicho" (11).

Muestra de modernidad lingüística, como ya indicó Frago Gracia (2007: 181), son los casos de pluralización del verbo impersonal haber "¿luego también debe de serlo que hayan hoi tantos maestros de estos primeros rudimentos" (25), "habla de los sucesos de la Iglesia... como los Papas que han habido" (34), "infinitos hombres sabios y curiosos que han habido en todas las edades y en todas las naciones de la tierra" (30), "afirman que en el Paraíso habian libros tocante (sic) a las ciencias y a las artes” (30), “¿y murieron también todos los animales que habían en aquel tiempo?" (31), "en las galerías del duque de Florencia habian, muy pocos años ha, unas peñas traidas de un cerro altísimo de la Fenicia" (32), "los Papas que han habido"

\footnotetext{
"En Hispanoamérica es general la confusión, y no ya sólo en el habla popular, sino también en la de ciertas personas cultas. La forma cualesquiera con un nombre en singular -intento de reponer una $-s$ allí donde se supone que pertenece al habla normal-puede convertirse en ultracorrección propia de regiones en que la -s final desaparece en la pronunciación" (1969: 182). Para mostrar esta confusión, Kany cita a Román, quien, refiriéndose al uso chileno, aconsejaba: "no olviden algunas personas, señoras sobre todo, que por lo demás no carecen de educación, que el plural de esta palabra es cualesquier o cualesquiera; pues ellas creen hacerlo mejor diciendo muy repulidas y con pésima concordancia: cualesquier día, cualesquiera cosita. Sin duda les parece que el singular cualquier, $-r a$, sólo es para los zafios que acostumbran no pronunciar la s" (citado en Kany 1969: 182).

8 Sobre este particular es oportuno recordar las palabras de Juan de Valdés (c. 1535/ 2003: 234-235), que mostraba ya cierta preferencia por la enclisis en casos similares a este último, concretamente con pronombres con función de objeto directo: "que se deve usar esta composición de la manera que digo, y no andar por las ramas como algunos, que por no hablar como los otros dizen por ponerlos, los poner, y por traerlas, las traer, etc. Es bien verdad que lo uno y lo otro se puede seguramente usar, pero el dezir ponerlos y traerlas a mi parecer es más llano y más puro, y aún más galano y más castellano".
} 
(34), etc., así como, en menor medida, del verbo hacer, "hacen 19 siglos a esta parte” (33), “¿según eso hacen mil ochocientos años a que murió J. C?" (33), un uso extendido en la actualidad, no ya solo en América $^{9}$,sino también progresivamente en territorio peninsular.

No obstante, frente a esos rasgos más innovadores también pueden encontrarse aún en esta época casos de la forma antigua $h a$, del impersonal haber ${ }^{10}$ "'ya da vergüenza el responderla después que $h a$ que la sabemos todos más de un año" (14), "¿y qué tiempo ha que se descubrieron estas Américas?" (22),"habían, muy pocos años $h a$, unas peñas traidas de un cerro altísimo de la Fenicia" (32), "¿y qué tiempo ha que escribieron esos autores que trataron a Jesu Cristo?" (33), "hacen mil ochocientos años $a$ que murió J. C.?" (33). En este último ejemplo se puede observar la redundante utilización de hacen (hacer) y a (haber). Kany (1969: 262, 263) explica cómo se produjo la duplicación y señala: "tales construcciones son actualmente corrientes en el habla popular de algunos de los países hispanoamericanos. El hablante, no dándose cuenta del valor de $h a$, pensó que se trataba de la preposición $a^{\prime \prime}(263)^{11}$.

También diverso fue el proceso de pronominalización del verbo a ambos lados del Atlántico,más fuerte en el español de América que en el de España (Frago Gracia 2010: 255), de tal forma que también es normal la aparición en nuestro texto de la forma aparecerse: "siempre se ha hecho salir a un demonio como encargado de la Escuela para impedir los adelantamientos y progresos y en este último se hayan aparecido dos más" (2), así como de seguirse 'continuar' en "pero ahora os seguiréis vosotros que lo sabréis hacer mucho mejor".

El fenómeno de la adverbialización de adjetivos tuvo en América más arraigo que en España, donde se está intensificando en la actualidad. Oroz

$9 \quad \mathrm{Al}$ respecto, Oroz observó lo siguiente: "la concordancia del impersonal (haber) con el sujeto aparente es lo común entre individuos de escasa cultura, pero en muchas regiones del país se observa también en personas ilustradas. Así este fenómeno se da en Punta Arenas y en Chiloé, como en el Centro meridional (Curicó), en grupos de todas condiciones" (381). Y más adelante indicó: "el verbo hacer impersonal suele convertirse en personal en el habla popular y no raras veces en la culta" (382).

10 Salvá (1847 / 1988: 313), al hablar de las estructuras impersonales, incluye "hace o ha seis años".

11 Continúa diciendo: "a algunos de los primeros gramáticos les indujo igualmente a error, como en el caso de Bello... Bello se equivocó al considerar este error como puramente chileno (si es que lo consideró así) y la $a$ como preposición. En la actualidad conocemos esta construcción en otras partes (Argentina, Ecuador, etc.) y es seguro que la $a$ se remonta al $h a$ original" (263). 
explica cómo "el uso de adjetivos como adverbios es un fenómeno de gran extensión en América" y especifica que "en el habla chilena es general" 12 . En nuestro documento encontramos el siguiente caso: "estáis satisfecho, Leviathan y señor Astaroth, que estudiamos historia, y que para de principio no está malo?” (34).

Entre las formas adverbiales reseñables en Campo podemos encontrar últimamente con la acepción de 'finalmente, por último término' (Autoridades) "estamos hoi tan dedicados al estudio de relijión, de moralidad y catecismos, como lo saben todos, sin olvidar ni la gramática latina, ni la aritmética, ni la geografía del país, ni la historia sagrada, y, últimamente, la buena, clara y lucida letra" (10), "y también le esplicara qué es Arte, qué es Música... y, últimamente, para no cansar qué es Mitolojía" (17), "dándonos a conocer los reinos, las ciudades, las provincias, los cerros... y, últimamente, las cinco partes de habitantes de que se compone la tierra" (20).

Encontramos además la locución adverbial de cantidad qué tanto 'cuánto', de la que Kany indicó: "es corriente en numerosas regiones de Hispanoamérica, y se la prefiere a las locuciones consagradas más generalmente usadas qué o cuán (cuánto) o alguna otra. Constituye aquel uso una supervivencia de la lengua antigua" (1969: 385) ${ }^{13}$. Los ejemplos hallados son los siguientes: “¿y qué tanto dista el sol de la tierra?” (21),“yo le preguntaré algo particular de lo que he estudiado, por ver qué tanto ha aprovechado V. con esa grande habilidad que Dios le ha dado" (15).

También aparece la locución luego que con el sentido de "inmediatamente que', mucho más usual por entonces en América que en España: "luego que supo Mardoqueo el terrible decreto contra él... se lo avisó a la reina"(39), así como la locución no más con su significado fundamental de 'solamente' que, como explica Oroz (353), "coincide en su uso chileno con el de la mayoría de los países de Hispanoamérica”: “¿y conchas y mariscos no más quedaron enterrados después que se pasó el diluvio?" (32).

Por otra parte, puede constatarse también la preferencia por la estructura segunda vez en lugar de por segunda vez, algo frecuente en textos de la época: "no pidió otra merced sino que fuese segunda vez a comer a su mesa" (40), “¿y fue segunda vez el rei con Amán..?” (40), “sí fue segunda vez el

12 "El caso inverso, o sea, el emplear adverbios como adjetivos, también es frecuente en el español de América" aunque "en Chile es propio más bien del lenguaje popular" (Oroz, 372).

13 El DRAE recoge la locución ¿qué tanto?, si bien la localiza únicamente en México. Una búsqueda en el CREA y en el CORPES nos confirma la preferencia actual de esta locución en territorio hispanoamericano. 
mismo día..." (40). Aparece además la estructura $y a+$ pronombre personal antepuesto al verbo, que era normal en el español clásico "y a América llega también sin connotación vulgar" (Frago Gracia, 2010: 110-111): “ya tú dijiste que son unas sentencias breves sacadas de la esperiencia de los tiempos" (18).

Destacable es, así mismo, la presencia de la expresión fija a nombre de en lugar de en nombre de, característica que pervive aún en el español de América, pero no en el de España, a pesar de que el $D R A E$ registra hoy ambas locuciones prepositivas sin ningún tipo de marca ${ }^{14}$. En Campo aparece a nombre de "pero para esta empresa necesitamos hoi, Ánjel Sagrado, toda tu protección y yo, a nombre de todos, te la pido" (29), pero, sin embargo, poco después vemos en nombre de: "y por esto Mandó Amán en nombre del mismo Rei... fuesen muertos todos los judíos" (37).

\section{FORMAS DE TRATAMIENTO}

Campo es, sin duda, un documento valioso para observar las formas de tratamiento personal, ya que, al tratarse de una representación teatral, son muy numerosos los diálogos. La obra comienza con la llamada de atención y el uso de vosotros y vuestro: "señores, aquí tenéis una grande obra que debe arrebatar vuestra atención, si sabéis apreciar lo que es digno de aprecio y meritorio en esta vida. Tenéis a la vista la obra grande, la benéfica, la útil, la necesaria y la sola en su especie de la enseñanza y educación de los niños" (5). Frago Gracia (2007: 177-178) explica el uso de vosotros en la época por el carácter formal de ciertos textos, así como también "porque pesaba mucho todavía la tradición literaria y el estilo oratorio", si bien acaba concluyendo: "pero es bastante seguro que en el primer tercio del siglo XIX todavía no fuera exclusivamente literario el uso de vosotros (y de vuestro)" ${ }^{15}$.

14 Un búsqueda en el CORDE revela que es muchísimo más frecuente la locución en nombre de que a nombre de, aunque tampoco puede ofrecernos una idea clara de su distribución a un lado y otro del Atlántico. A nombre de en España se halla en textos notariales arcaizantes del siglo XIX.

15 El mismo autor, en 2011 (57), dice: “aunque el pronombre vosotros, y correlativamente el posesivo vuestro, puede encontrarse en no importa qué texto de la época de la Independencia, lo cierto es que su aparición se da con mayor profusión, incluso con regularidad, en los de carácter oficial, de estilo por lo general muy tradicional, en los doctrinales o marcados por la 
A continuación de la apelación que hace el Padre Mújica, se inicia un diálogo interesantísimo entre un ángel y varios demonios. Uno de los diablos, levantándose de su asiento, dice: "de todas ellas (las legiones del infierno) necesita mui bien cada uno de vosotros, para sujetaros a nuestra voluntad" (8). A esto responde el Ángel, tratando de vos al demonio, y utilizando lo que parece un voseo de respeto con un personaje de cierto rango, el Capitán de Roma: “callad, y continuad vuestro discurso, Capitán”. Dicho capitán, avergonzado por la existencia de tantos diablos en la escuela, se excusa y, tuteando al Ángel, le dice: “y a tí, Ánjel soberano, pertenece sin duda sacarnos hoi de este tropiezo, y hacer con $t u$ poder y con $t u$ fuerza que ellos mismos nos digan..." (8). También tutea el diablo Leviathan al Ángel: "bien sabido es a tí, Ánjel, a todo el cielo y al abismo, que yo soy el antiguo y grande Leviathan... y este otro a quien buscamos este día es el sagaz y el astuto Asmodeo... como tú sabes" (8).

El Ángel, que, como vimos antes, trató de vos a Leviathan, le pregunta a Astaroth: "y ese $t u$ libro, qué contiene?" (9), a lo que responde este: "lo mismo...y puedes rejistrarlo si te agrada". A partir de aquí todos los personajes se tutean: el Ángel, los demonios, el Capitán de Cártago ${ }^{16}$ : "bien te conozco y no son por eso tus esfuerzos sino por apartarlos de la moralidad y la virtud y porque sabes que la ciencia sin el temor de Dios es como árbol sin fruto... pero yo te juro por el Cielo que sin que pase mucho tiempo se han de ver estos valles sembrados de jóvenes virtuosos y has de ver por tus ojos que del rancho y chacra más humilde se forman... hombres de luces y virtud". El voseo del Ángel es, por tanto, muy escaso: "tenéis razón de apoyar cuando condena a la ruina y perdición del hombre" (28) y "continuad vuestras respuestas, Leviathan" (37).

No obstante, las formas de tratamiento cambian en la siguiente escena, cuando Asmodeo interroga a los alumnos sobre las verdades de la fe católica y usa el vos con ellos: "y vos, para qué lo decís (el credo)?" (11), “creislo?" (11) ,"Por qué lo creis?" (11) ${ }^{17}$. En ocasiones se mezclan formas de tuteo y voseo: "viste vos nacer a J.C.?" (11),"eso no me lo preguntéis a mí que soi ignorante, doctores tiene la Santa Madre Iglesia que te sabrán responder" (14).

erudición, y en aquellos envueltos de solemnidad, que también pueden buscar, curiosamente, el acercamiento emocional a los destinatarios cuyos ánimos se desea enfervorizar y conquistar.

${ }_{16}$ En otra ocasión dirá el Capitán de Cártago, dirigiéndose al Ángel: "pero para esta empresa necesitamos hoi, Ánjel Sagrado, toda $t u$ protección y yo, a nombre de todos, te la pido" (29).

17 En todo momento se registra la forma vulgar creís en lugar de creéis. 
En otro pasaje asistimos al ustedeo entre el Porro y el Hábil (el alumno torpe y el aplicado); este último le pregunta al primero: "yo quisiera saber por qué lo llaman el Porro?" (14), a lo que este le contesta que es debido a su mala memoria, y a ello apunta el Hábil: "pero tendrá tal vez mui buen entendimiento..." (14). A continuación se suceden entre ellos casos de ustedeo: "qué es lo que sabe mejor para poderle preguntar?" (15), "pregunte $V$. lo que quisiere, que yo responderé lo que supiere" (15), "¿y sabe la Doctrina Cristiana?" (15). No obstante, en cierto momento el Hábil cambia la forma de tratamiento al vos, quizás motivado por el hecho de que se usa seguido de un vocativo: "pues decidme, hijo, hai Dios?". Se trata este de un caso aislado, porque continua tratándolo de usted: "le preguntaré", "qué quiere que le pregunte con mil santos para que veamos lo que sabe?", "y si $V$. me permite, yo le preguntaré algo particular de lo que he estudiado, por ver qué tanto ha aprovechado $V$. con esa grande habilidad que Dios le ha dado" (15), “y, dígame ¿qué entiende $V$. por relijión? (16)”, etc.

Son muchos los conocimientos que demuestra conocer al que llamaban Porro, y el diablo Asmodeo, enfadado, le grita: “calla, niño, no sigas adelante, mira que me estás quebrando el corazón... Y si supieras Porro estos refrancitos... no te apuraras tanto en estudiar y en calentarte la cabeza para hacerte tal vez más incapaz" (17). Se sucede el tuteo y solo destaca lo que dice el Ángel, mezclando voseo y tuteo (a Asmodeo, el diablo): "obrad como quisieres y probad su capacidad como te agrade, y aún te permito que subas a la cátedra" (18); después continúa, sin excepción, el tuteo entre demonios.

Finalmente aparecen otros dos personajes subidos a su respectiva cátedra, el Pobre y el Rico. El rico trata de tú al pobre: " ¿a qué has venido a meterte a esta escuela en ese estado de miseria y has dejado a tus padres que perezcan?" (24), mientras que el pobre le concede el tratamiento de usted: "no tengo esos vestidos que $V$. tiene porque soi forastero". Sin embargo, al final de su intervención, el rico le otorga el usted al pobre y le dice: "si $V$. es pobre, amólece y estudie hasta que el diablo se lo lleve".

Los alumnos, cuando tienen la posibilidad de hacer preguntas, también se dirigen con el tú a los diablos: "tengo a gran felicidad, Señor enviado, que un personaje como tú sea hoi mi condiscípulo y que estés agregado a nuestra escuela, pues se nos ha enseñado que vosotros, los diablos, aunque perdisteis la gracia, no perdisteis la ciencia, y me sabrás decir seguramente y explicarme muchos de los pasajes que nos cuenta Moisés en el libro del Génesis" (34-35). El diablo también le contesta con tú: "y ¿hasta cuándo me preguntas, niño, que ya me tienen ronco tus preguntas"? (36), etc., si bien en cierto momento -nótese, de nuevo, el vocativo- le dice el diablo al niño: "pues preguntadme, niño, hasta mañana, que al cabo te has de canzar de preguntar" (37). Prosigue el tuteo entre ambos, aunque en alguna ocasión 
puede añadirse la forma vos: “ ¿y viste vos ese pasaje de aquel día y conociste a Amán y a Mardoqueo?" (38). Como ya se vio, entre los diablos también se daba el tuteo, pero en cierto momento se inserta un tratamiento de vos mezclado con tuteo: "pero venid, tú, Leviathan y pregúntales uno por uno la tabla de salteado" (46).

En un principio puede parecer caótica la suma de tratamientos que acabamos de exponer, sobre todo porque a veces aparecen mezclados. De este modo, vimos que en ocasiones se combinan formas de voseo y tuteo, lo que nos recuerda al voseo mixto tan generalizado hoy en Chile, y que se denomina así porque el pronombre singular tú se construye con formas verbales derivadas de la segunda persona plural, del tipo "tú no estái bien" Por otra parte, se pueden observar ciertas tendencias. A los diablos suele tratárseles de tú o de vos, porque se les considera personajes de clase baja; así mismo, los demonios suelen usar estos mismos tratamientos para hablarse entre ellos, o bien referirse a los alumnos. El mismo tratamiento se le da al alumno pobre, a pesar de tener una edad similar que el alumno rico, al que, por su estatus económico, se le concede el usted.

\section{ALGUNAS CUESTIONES LÉXICAS}

En Campo encontramos palabras de origen indígena como el quechuismo chacra o chácara 'finca rural', voz muy frecuente en la documentación de la época:"en un día de campo que tuvo en esta chacra o convento" (1) ${ }^{19}$.

18 Torrejón indicó (2010: 768): “el voseo mixto verbal, universal entre los jóvenes de sectores cultos de las décadas de 1960 y 1970, se ha extendido a otros sectores etarios como forma de tratamiento solidario en el trato íntimo entre personas de un mismo grupo de edad e igual estatus social. Esto no ocurre solamente entre las personas cultas de las áreas urbanas, más importantes, sino que se ha irradiado a otros sectores sociales y a comunidades alejadas de los centros urbanos. En intercambios con gran contenido emocional, los hablantes que habitualmente usan el voseo mixto verbal llegan a recurrir al voseo auténtico".

19 El DCECH da la siguiente explicación: "en los cronistas del siglo XVI predomina la forma con anaptixis chácara. Hoy todavía, en la Argentina, se vacila entre chacrita y chacarita, y en todas partes se emplea sólo chacarero... Es de las pocas voces quichuas que se han extendido hasta Costa Rica, Guatemala y el Salvador; también al Brasil, y es general en América del Sur". Según Morínigo, la voz pervive en toda América Central y en la Meridional, con excepción de Paraguay, pero el $D A$ también lo registra en este último país. Son numerosos los ejemplos que de esta voz recoge Boyd-Bowman ya desde el siglo XVI y XVII en Perú. Por mencionar uno de Chile, de 1842: "todos... hablen de la hacienda, la chacra, la quinta". 
Otra voz de origen quechua es huanaco o guanaco 'mamífero rumiante'20, que aparece en el documento en su segunda acepción con sentido figurado 'tonto, simple' cuando un diablo le dice a un niño:"tú no la tendrás (la inteligencia), huanaquillo montarás de estas sierras" $(19)^{21}$. De posible origen quechua es también la palabra guaso 'campesino' con diminutivo ${ }^{22}$ : "pero estos guasocitos que ayer no sabían leer, ni como se llamaban, hoi veo lo que saben" (40). Procedente del mapuche es la voz chatre, adjetivo que, según Morínigo y Medina, significaría "elegante, acicalado, especialmente el huaso endomingado; lo contrario de chegre"23: "el pobre en su cátedra y el rico en la suya, el uno mui roto y el otro muy chatre" $(24)^{24}$.

Por otra parte, no es extraña la aparición en Campo del americanismo general plata con el significado de 'dinero', 'monedas':"para eso soi rico y tengo plata" (27), y de rancho, voz que en origen se trata de un andalucismo léxico ${ }^{25}$ y que es definida por Morínigo como 'habitación rural de gente pobre. Las paredes son generalmente de adobe o de barro mezclado con paja, los techos de paja o de totora, sostenidos con horcones. El suelo es de

20 Tiene muchos registros desde el siglo XVI en Boyd-Bowman. Medina indica en la introducción de su obra (1928: XVII): "tratándose de las voces de procedencia indígena, hemos de acatar el acuerdo de la Facultad de Filosofía y Humanidades de la Universidad de Chile, que prescribió el uso de $g$ antes de $u a$, y el de la $h$ antes de $u e$ y de $u i$ ".

${ }^{21}$ Este sentido figurado también lo recoge Medina situado en América Central y Meridional. El guanaco, uno de los animales más característicos de Chile y Argentina, se toma como punto de comparación en numerosos contextos, en un nivel popular. Así, dice Martín Fierro: "ni un pedazo de tabaco / le dan al pobre soldao / y lo tienen de delgao / más lijero que un guanaco" (vv. 789-792).

22 Morínigo lo define como "campesino chileno, labrador o vaquero, y en general todo hombre de pueblo rudo y sin educación que no sea trabajador o artesano de la ciudad' y explica: "se ha propuesto para esta voz la etimología huasu, que aparece en Middendorf como voz quichua. Pero la voz pudo ser de otro origen y pasar del español al quichua, en vista de estar documentada hacia 1740. Corominas cree que la voz puede ser americana de origen antillano, en razón de su difusión". Boyd-Bowman tiene registros de huaso (solo en Chile), así como de la variante guaso, ya también en otros países. Por poner algún ejemplo: "someterse a ese guaso degollador, ladronazo" (1843, Uruguay), "guaso: hombre rudo y grosero, es usada también en Chile. Hombre tosco, incivil" (1982, Bolivia).

23 Ambos autores antes mencionados localizan el uso de este adjetivo en Ecuador y Chile. En Boyd-Bowman aparecen dos referencias, de las cuales una parece adecuarse a esta significación: "hablando de tales cosas (no) podrá contener sus lágrimas, aunque sea un gallinazo o un chatre, que son de nuestros soldados los más guerreros e indolentes" (1794, Lima).

24 Para Oroz chatre y chegre son quechuismos (408).

25 Como explica Frago Gracia en "Rancho 'vivienda rural o finca de campo': un andalucismo léxico más del español de América”, Revista de Filología Española 71, 1991, pp. 339-345. 
tierra apisonada'. Son varios los ejemplos que aparecen en el documento: "nuestros padres, amados condiscípulos, no serían hoi habitadores de esas chozas y ranchos miserables" (5), "siendo de notar que los padres más pobres y gañanes se hayan sacrificado a costear a sus hijos la estación de ellos a las inmediaciones de esta escuela, como que hoi se hallan 21 niños en diversos ranchos de esta chacra" (7).

Se encuentra también en nuestro texto la voz llamado con el significado de 'llamamiento' -en otros textos de la época aparece con el significado de 'convocatoria'-: “¿y a qué fin fue este llamado de la reina?”, “¿y vino la reina a la mesa del rei y a su llamado?" (35) ${ }^{26}$. Así mismo, en el documento se puede leer: "las simarras que ellos han hecho (vienen apuntadas en el libro) y otras menudencias tan curiosas que algún día pueden salir a luz si hoi no alcanzasen a salir" (10). Medina explica cómo "hacer la cimarra" es una expresión que se utiliza cuando el estudiante, en vez de ir al colegio, se marcha a otra parte". Entre las referencias que recoge este autor, significativa es la que sigue: "la cimarra, sustantivo chileno derivado del adjetivo cimarrón, fue seguramente inventada para los niños de mi tiempo" (de Pérez Rosales) ${ }^{27}$.

Son varios los significados que puede tener la voz roto. En Chile se utiliza para denominar al 'hijo del pueblo', mientras que en Argentina y Perú se utiliza como forma despectiva para llamar al chileno (Medina y $D A)^{28}$. Como adjetivo, suele aparecer a veces con el sufijo -oso y se utiliza en México, Perú y Chile para denominar a una persona de clase social baja $\mathrm{y}$, en ocasiones, a una persona maleducada y de modales groseros ${ }^{29}$. No obstante, los registros que encontramos en Campo aluden únicamente a la pobreza del individuo: "el pobre en su cátedra y el rico en la suya, el uno mui

26 Véanse ejemplos de Frago Gracia (2010: 196). Hoy el $D A$ sitúa en Panamá, Chile y Paraguay además la significación de 'comunicación telefónica o de otro tipo'. Así, por ejemplo, en Chile existen centros de llamado, denominados locutorios en España.

27 Otras obras ofrecen explicaciones similares, si bien añaden otras localizaciones a las chilenas (el $D R A E$ también la localiza en Argentina y el $D A$ en Uruguay). Boyd-Bowman solo registra la siguiente entrada en 1862 (en Chile): "pasaba... los años de su turbulenta niñez en una perpetua cimarra". Recordemos que la voz cimarrón (usual en América desde el siglo XVI) se utilizaba para designar al "alzado, montaraz, aplicado a los indios, negros y animales huidos a los montes y cerros" (Morínigo). Aparece esta voz, por ejemplo, en el Martín Fierro: "Ya andaba desesperao, / aguardando una ocasión; / que los indios un malón / nos dieran y entre el estrago / hacérmeles cimarrón / y volverme pa mi pago" (vv. 799-804).

28 Un registro de Boyd-Bowman con este significado se halla en Buenos Aires, en 1870: "es un roto chileno, vivo como un rayo".

29 Morínigo, por ejemplo, explica que se trata del 'individuo de la clase más pobre e ineducada'. 
roto y el otro muy chatre" (24), y con diminutivo -ito en: "a ella le habían dado como escalofríos de ver tanto rotito saber tanto" (49) ${ }^{30}$.

Significativo es el verbo taimarse, que, procedente del gallego-portugués teima según el $D R A E^{31}$, se utilizaría en Bolivia y Chile para significar 'amorrarse': 'bajar la cabeza, obstinándose en no hablar'. Morínigo define taima como 'murria, emperramiento; obstinación de una persona malhumorada'. Hay un pasaje en el impreso Campo en que se utilizan mucho estas voces con dicho significado: "aunque nos ha dicho Leviathan que tú eres el taimado Astaroth, aquí no valen taimas porque las pagarías de contado" (39), "mi Capitán: Astaroth se ha taimado", "¿te has taimado Astaroth?... ¿Qué es esto Astaroth? ¿Estás taimado?" "No estoi taimado, sino pensando y meditando cosas grandes" $(40)^{32}$.

Aparece en Campo también la forma plumario, de la que ya el Autoridades indicó: 'lo mismo que plumista, que es como se dice' ${ }^{33}$. Medina indica que se trata de una palabra despectiva para referirse a "el que escribe en los periódicos y está asalariado para defender a una persona o cosa que le interese". También despectiva para Morínigo, viene localizada por este en Guatemala, Méjico, Panamá y Nicaragua. Sin embargo, no creemos que tenga un sentido despectivo en la siguiente referencia, sino más bien se trataría de un uso tradicional: " $¿ \mathrm{y}$ no es del orden natural que los buenos lectores y los buenos plumarios y de buenas y arregladas cuentas sean los que se ocupen y coloquen en la dependencia de martillos, almacenes y tiendas...?" (25).

Por otra parte, hay que tener en cuenta también en estos temas léxicos, como también importante es en gramática, la cuestión de grado. En Campo encontramos dos voces que, si bien también se conocen en el español peninsular, tienen en Hispanoamérica un mayor uso. Hablamos, por tanto, de

30 También la gran parte de registros de roto en Boyd-Bowman se refieren a la miseria: "el enlutado roto iba rengueando en medio de nosotros dos" (c. 1816, México), "todo se vuelve apariencia, y en lo interior pasan sus miserias bien crueles. A éstos llaman rotos" (c. 1816, México), "sólo es visitado por las damas los domingos: en los días restantes de la semana, sólo se ven los rotos" (c. 1840, Chile). Rotoso lo encontramos en el Martín Fierro, cuando el negro le dice al gaucho: "-Más porrudo serás vos, / gaucho rotoso-" (vv. 1181-1182).

31 Sobre el origen portugués de esta palabra véase también el $D C E C H$ y Frago Gracia (1999: 153 y 154). En Chile, taima significa 'murria, emperramiento'. Otras obras dan una definición similar de taima y taimarse (Medina, $D A$, etc.)

32 No obstante, taimado también significó en Argentina y Ecuador 'perezoso' (Morínigo), de ahí la referencia que recoge Boyd-Bowman, de Venezuela en 1759: "(indios) flojos, perezosos, taimados (y) astutos".

33 Aunque aún hoy se mantiene en el DRAE la entrada plumario como palabra anticuada. De las diez referencias que recoge el CORDE, siete son de autores peruanos (entre $1781 \mathrm{y}$ 1889). 
preferencias léxicas ${ }^{34}$. Un caso llamativo, ya estudiado ampliamente, es la voz lindo en lugar de bonito: "no es posible, sin verlo, formar concepto de esto, esto es muy lindo" (49) y flojera en lugar de pereza en "y si no fuera pecado el maldecir, aquí maldijera mi suerte y mi flojera, y no mi entendimiento y mi memoria" (17), "pues no hai, señor Hábil, que aburrirse ni maldecir a su flojera, sino enmendarse en adelante y estudiar algo más" $(17)^{35}$.

Así mismo, es preciso tener en cuenta la sufijación. En cuanto a los diminutivos, es bien sabido que el sufijo preferido en casi toda Hispanoamérica es -ito, del que encontramos varios casos en este impreso. Este sufijo es usual para marcar afectividad, como en los siguiente ejemplos: "como parece que en estos tiempos no se pensase por dicha en otra cosa que en la educación... no solo en la juventud de esta capital de Chile, sino también en todos los puntos de la república y aun en los más pequeños pueblecitos" (1), "ha querido estampar en este cuadernito uno de los actos públicos" y "lo que se verá en este cuadernito" (1), "el alivio que los grandecitos (los hijos mayores) suelen dar a sus casas" (2), "¿y qué quiere decir aunque juegues con tu hermanito dale un barajito?" (18); pero también se encuentra este sufijo para indicar ironía: "y si supieras, Porro, estos refrancitos, que son breves sentencias..." (17).

En Campo aparece también el sufijo aumentativo -azo con tono despectivo en la oración "¿no has visto el cuadrillazo que me han dado?" (49). Kany (1962: 95 y 96) indica que "este uso se prodiga mucho en América, especialmente en el habla popular y rústica de las regiones del Río de la Plata y Chile". Finalmente, se puede destacar la aparición del sufijo -ista, de gran creatividad en la época estudiada: "juro por el infierno que en eso no he mentido y que jamás os he dejado estudiar catecismos, ni esos libros de beatos y de beatas; y, si no basta mi verdad, que vengan esos catecimistas" (11).

34 Este asunto ya fue mencionado por Kany en su Semántica hispanoamericana (1962: 5 y ss.), por aducir solo una referencia.

35 Dice Hildebrandt (1961: 298): "en gran parte de América flojo ha llegado a hacerse sinónimo de perezoso. Este matiz... estaba latente en algunos usos españoles”. También explica que flojera es igualmente en gran parte de América sinónimo de pereza, matiz que difiere del académico 'flojedad, laxitud'. 


\section{PARA CONCLUIR}

El Nuevo Método de Educación para el uso de las Escuelas del Campo es un documento de indudable valor para conocer las técnicas de enseñanza que se empezaban a utilizar a comienzos del siglo XIX en un intento por alejarse de los antiguos métodos escolásticos. De un modo práctico, su autor, el Padre Mújica, presentaba los contenidos que los alumnos debían aprender en la escuela, quedando, de este modo, plasmados para la posteridad. Leyendo la obra teatral en la que desfilan personajes de lo más variopinto, el estudioso actual puede ver el punto concreto en que se encontraban algunas ciencias como la geografía, y las creencias que se tenían sobre muchas materias.

El método dialógico presenta además incontables ventajas para el análisis lingüístico. La sucesión de preguntas y respuestas -aunque sea de forma ficticia-crea una situación en la que los personajes, pertenecientes a esferas socioculturales muy distintas, han de interactuar entre ellos otorgándose una forma determinada de tratamiento. Ello nos ofrece una clara imagen de cómo es cada personaje y de cómo se le considera socialmente, lo que nos ayuda a establecer jerarquías. Aparecen personajes procedentes de dos mundos, el terrenal y el celestial-infernal, si bien a los personajes de este último se les atribuye comportamientos y rasgos humanos, y sus acciones se miden y califican de acuerdo a normas sociales terrenas. De este modo, voseo, tuteo y ustedeo se suceden a lo largo de las páginas, muchas veces mezclados en sus formas, entre alumnos, diablos y ángeles.

Pero además de las formas de tratamiento, el documento aporta otro tipo de datos gramaticales significativos para situar su origen en el sur del continente americano, tales como los casos de pluralización de los verbos impersonales haber y hacer, de la forma pronominal aparecerse, de la adverbialización del adjetivo en "está malo", la locución no más o la estructura "ya tú dijiste". Por otra parte, el análisis del léxico también nos ofrece datos para localizar este texto, ya con el uso de americanismos generales como plata, rancho o la extensa utilización del sufijo -ito, y, más concretamente, con la utilización de formas más restringidas al país chileno como roto y chatre. 


\section{REFERENCIAS BIBLIOGRÁFICAS}

AURORA DE CHILE. 1812-1813. [Ejemplares en línea]. Disponible en http://www.aurorade chile. $\mathrm{cl} /$ newtenberg/681/propertyname-699.html.

AUTORIDADES (v. Real Academia Española). 1726-1739.

Bello, AndRÉs. 1843 / 1981. Discurso pronunciado en la Instalación de la Universidad de Chile el 17 de septiembre de 1843. Antología General de Andrés Bello. Tomo II, pp. 1451-1468. Madrid: Editorial Mediterráneo.

Boyd-Bowman, Peter. 2003. Léxico Hispanoamericano (1493-1993). Ray Harris-Northall y John Nitti (eds.). CD-ROM. New York: Hispanic Seminary of Medieval Studies.

Corominas, Joan y José Antonio Pascual. 1980-1991. Diccionario crítico etimológico castellano e hispánico. Madrid: Gredos.

DA: Diccionario de americanismos (v. Real Academia Española).

DCECH: Diccionario crítico etimológico castellano e hispánico (v. Corominas y Pascual). 1980-1991.

Feliú Cruz, Guillermo (ed.). 1966. El redactor de la educación. 1825. Colección de antiguos periódicos chilenos, 20. Santiago de Chile: Ediciones de la Biblioteca Nacional.

Frago Gracia, Juan Antonio. 1999. Historia del español de América. Textos y contextos. Madrid: Gredos.

2007. Tradición e innovación en el español americano de la independencia. Romance Philology 61, pp. 147-191.

2010. El español de América en la Independencia. Santiago de Chile: Taurus.

2011. El español de América en la Independencia. Adiciones gramaticales. Boletín de Filología 46, $\mathrm{N}^{\mathrm{o}}$ 1, pp. 47-74.

Hernández, José. 1872 / 2003. Martín Fierro. Luis Sáinz de Medrano (ed.). Madrid: Cátedra.

Hildebrandt, Martha. 1961. La lengua de Bolivar. 1. Léxico. Caracas: Universidad Central de Venezuela.

Kany, Charles E. 1962. Semántica hispanoamericana. Madrid: Aguilar.

1969. Sintaxis hispanoamericana. Madrid: Gredos.

Medina Zavala, José Toribio. 1928. Chilenismos. Apuntes lexicográficos. Santiago de Chile: Comisión oficial organizadora de la concurrencia de Chile a la exposición IberoAmericana de Sevilla.

Morínigo, Marcos A. 1998. Nuevo diccionario de americanismos e indigenismos. Buenos Aires: Claridad.

Oroz, Rodolfo. 1966. La lengua castellana en Chile. Santiago: Facultad de Filosofía y Educación, Universidad de Chile.

Real Academia Española. 1726-1739 / 1969. Diccionario de Autoridades. Madrid: Gredos.

Diccionario de la Real Academia Española (DRAE). [en línea]. Disponible en http://web.frl.es/dh.html.

Banco de datos (CORDE). Corpus diacrónico del español [en línea]. Disponible enhttp://www.rae.es.

Banco de datos (CORPESXXI). Corpus del español del siglo XXI [en línea]. Disponible en http://www.rae.es.

Banco de datos (CREA). Corpus de referencia del español actual [en línea]. Disponible en http://www.rae.es.

2010. Diccionario de americanismos (DA). Madrid: Asociación de Academias de la Lengua Española. 
Salvá, Vicente. 1847 / 1988. Gramática de la lengua castellana. Margarita Lliteras (ed.). Madrid: Arco Libros.

Torrejón, Alfredo. 2010. Nuevas observaciones sobre el voseo en el español de Chile. Formas y fórmulas de tratamiento en el mundo hispánico. Martin Hummel, Bettina Kluge, María Eugenia Vázquez Laslop (eds.). México, D.F.: El Colegio de México, Centro de Estudios Lingüísticos y Literarios, pp. 755-769.

VAldés, JuAn De. c.1535 / 2003. Diálogo de la lengua. Cristina Barbolani (ed.). Madrid: Cátedra. 